\title{
CALPHAD Approach to Understand the Semi-Solid Processing Parameters of Al-6Si-4Cu Alloy
}

\author{
Gopalakrishnan $\mathrm{P}^{1}$ and Senthilkumar $\mathrm{M}^{2}$ \\ \{pgk.metal@psgtech.ac.in ${ }^{1}, \operatorname{msk} . p r o d @ p s g t e c h . a c . i n^{2}$ \} \\ Department of Production Engineering, PSG College of Technology, Coimbatore - $641004^{1}$
}

\begin{abstract}
Semi-solid processing has some prerequisites such as the feedstock alloy must meet certain thermodynamic criteria. Therefore, to reap the full benefits of semi-solid processing, it is important to assess the compliance of commercial aluminium alloys for semi-solid processing. Hence in the current paper, thermodynamic parameters for semisolid processing of $\mathrm{Al}-\mathrm{xSi}-\mathrm{yCu}(\mathrm{x}=5,6,7$ and $\mathrm{y}=3,4,5)$ alloys were assessed using CALPHAD approach. The results show that the thermodynamic simulation is effective in predicting the amenability of alloys for semi-solid processing. Also inferred that the variation of alloy composition within the ASTM standard range itself varies the solidification behaviour and this variation can affect semi-solid processing. Thus, a Taguchi L9 orthogonal array is constructed for various alloy compositions and based on the L9 array, the solidification curves were simulated by CALPHAD Approach. The best suited alloy and its thermodynamic parameters for semi-solid processing were identified. The simulated data for the best alloy composition is validated with the help of computer aided cooling curve analysis.
\end{abstract}

Keywords: Semi-solid processing; CALPHAD; Solid fraction; Aluminium alloys; Solidification.

\section{Introduction}

Semi-solid processing is an emerging field of metal processing route where the material is formed in its semi-solid state to get a near shaped component[1]. The basic science behind semi-solid processing is the 'thixotropic and pseudo-plastic behaviour' of non-dendritic micro structured alloys in their semi-solid state[2]. Semi-solid processing is advantageous over conventional casting as the presence of solid particles in the liquid slurry with a higher viscosity than pure liquid leads to controlled die filling and reduced porosity[3], [4]. However, a comparatively lower forging pressure than the conventional forming process can reduce die wear[4]. Semi-solid processing is divided into two categories; rheocasting and thixoforming[3]. Rheocasting involves cooling of molten alloy into a semi-solid condition and processing at its mushy zone[5]. Thixoforming involves controlled heating of non-dendritic billet into semi-solid range and forming into required shape[6].

In both processes, the material will be processed to a required shape in its semi-solid state[7]. Current commercial alloys are designed either for casting or forming processes[8]. These alloys can have compatibility issues with semi-solid processing. An alloy's flexibility towards semi-solid processing depends on parameters such as solidification range, fraction liquid sensitivity and window processing temperature[9], [10]. The literature points out that, most of the semi-solid processing studies were reported with commercial alloys such as 
Aluminium A356, A357, 6082, 7075, 206 and Mg alloys such as AM60, etc. However, except for A356 alloy the other alloy systems have practical challenges in semi-solid processing such as lack of process control, hot tearing, lack of fusion etc. [9]-[12]. Hence, to assess the alloy compatibility, it is vital to understand the phase transitions involved in the alloy system, understanding of initial microstructure and its rheological behaviour. A thorough understanding of the thermodynamic behaviour and phase transformations in the alloy during solidification and reheating are key factors that help to design a new alloy or select or redesign an existing alloy for semi-solid processing. Alloy compatibility assessments for the semi-solid processing are generally carried out by identifying their thermodynamic parameters such as solidification range, fraction solid sensitivity and processing window temperature[9].

Tzimas and Zavaliangos reported that usage of thermodynamic simulation is time conserving and authentic in the prognosis of solidification behaviour of materials and hence effective in alloy design[13]. Recently Zoqui et.al also reported DSC calorimetric studies have good match with thermodynamic modelling[8]. But in solidification studies computer aided cooling curve can acquire more information which may not possible in calorimetry[14]. CALPHAD approach (CALculation of PHAse Diagrams) is an effective method for quantitative modelling of thermodynamic data for applications like solidification analysis and alloy design[8], [11], [12], [15]. Phase composition identification in multi-component alloy, based on the Gibbs energy minimization is the key concept of CALPHAD approach. CALPHAD approach is capable to simulate non-equilibrium solidification behaviours using the Scheil-Gulliver equation[15], [16]. Thus, CALPHAD approach is a very useful tool for calculating the semi-solid processing parameters. Thermo-Calc is a software which works for CALPHAD approach implementation[8]-[10], [12], [17]. Thus, in the present work, by considering the commercial importance of semi-solid processing of $\mathrm{Al}$ alloys in transport industry, an attempt has been made to evaluate semi-solid processing parameters for Al-6Si$4 \mathrm{Cu}$ alloy by CALPHAD approach. Further, in the present study, an attempt has been also made to validate the simulation data with the cooling curve method of solidification analysis.

Thermodynamic criteria for semi-solid processing

Majority of aluminium alloys on the market are designed as suitable either for casting or forming processes. These alloys may find difficulties to fit and or meet the criteria of semisolid processing. Hence, to evaluate or design alloys for semi-solid processing, certain thermodynamic criteria have been reported in the literature and they are summarized below.

Range of Solidification Temperature $\left(\Delta T_{S-L}\right)$

Range of solidification temperature $\left(\Delta T_{S-L}\right)$ is the difference in temperature between liquidus and solidus of an alloy for a specific composition. The range of solidification temperature depends on the processing conditions and the composition of the alloy. Alloy with a narrow freezing range solidifies quickly and it can reduce the control of processing temperature at semi-solid state. Conversely, a too wide temperature range may reduce the fluidity of the slurry and makes it susceptible to hot cracking. The ideal solidification temperature range for semi-solid processing is $30-120^{\circ} \mathrm{C}[11]$.

Working Window Temperature $\left(\Delta T_{w w}\right)$

The operating temperature window is also alternatively called as the working temperature window $\left(\Delta T_{w w}\right)$. A fairly large operating temperature window is expected since the temperature can fluctuate during the semi-solid processes. In the industrial perspective, the ideal solid fractions for rheocasting and thixoforming are 0.3 to 0.5 and 0.5 to 0.7 respectively. Thus, for rheocasting, $\Delta T_{w w}$ can be defined as the temperature interval corresponding to solid fractions between 0.3 and 0.5 . Similarly, for thixoforming, $\Delta T_{w w}$ will be the temperature interval for solid fractions ranging from 0.5 to $0.7[9]$, [10]. 
Temperature sensitivity of Solid fraction or Fraction solid sensitivity ( $\left.d f_{s} / d T\right)$

Fraction solid sensitivity is the slope of the solid fraction $\left(f_{s}\right)$ vs. temperature $(\mathrm{T})$ curve in semi-solid region. During the solidification of molten alloy; the rate change of solid fraction for the temperature will be negative. In order to express the slope value as a positive fraction, a minus sign will be added in front of the equation; i.e. $-d f_{S} / d T$. This point out that temperature sensitivity can be interpreted as the change in the solid fraction per unit temperature during the course of solidification. Therefore, a minimum value of $d f s / d T$, which should remain approximately constant throughout the process, is recommended for better process control. Liu et al. suggest that $d f_{S} / d T$ less than 0.020 is preferred for semi-solid processing. It indicates that the overall change in solid fraction should be less than $2 \%$ throughout the semi-solid processing temperature range[8].

The Highest Knee point

The knee point represents the point at which $\alpha$-solid solution starts melting in binary eutectic systems[12]. The different eutectic reactions and knee point in Al-7Si-0.3 Mg alloy are shown in Fig. 1 for better understanding.

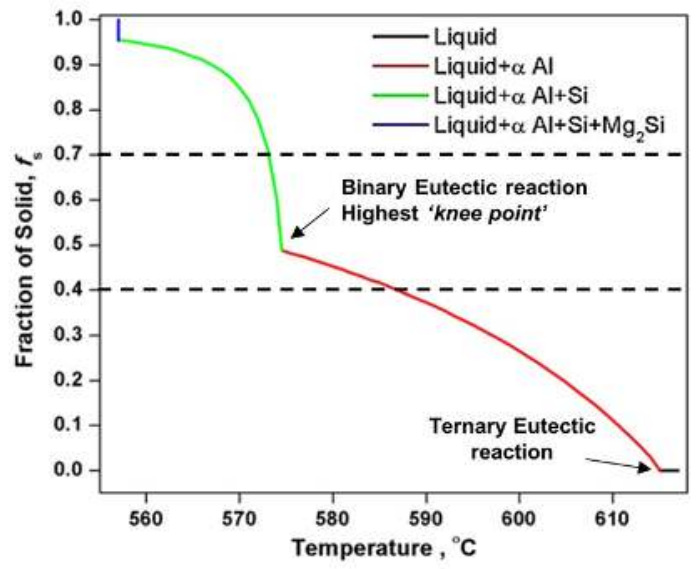

Fig.1. A typical fraction of solid versus temperature curve with knee points [17]

According to literature, this binary eutectic reaction should occur at a solid fraction range of 0.4-0.7. Further, if the knee point locates out of the suggested range; the phase transformation will not be in control and it affects the yield and quality of thixoforming[12].

Therefore, in this research, the authors focus on the thermodynamic simulation of the solidification properties of the selected alloy in order to know the four parameters given above. Thermodynamic prediction allows identifying and/or studying the solidification parameters without preparing the actual alloy. This will be beneficial for developing new alloys and also for modifying the composition of the alloys to make them compatible with semi-solid processing. Literature prefer Scheil-Gulliver's model over the Lever rule model for thermodynamically predicting solidification behaviour since it is more realistic than the Lever rule model. The mathematical representations of Scheil's model are given in Equation (1) to (3)[12].

$$
C_{S}=k C_{o}\left(1-f_{S}\right)(1-k)
$$


where, $C_{s}$ is the composition of solid, $f_{s}$ is the fraction of solid, $C_{o}$ is the overall composition of liquid alloy and $k$ is the partition coefficient. Equation (1) is formulated with an assumption that solute diffusion in solid state is negligible. In order to find the fraction of solid $\left(f_{s}\right)$ and fraction of liquids $\left(f_{L}\right)$ at a given temperature T, Equation (1) can be rewritten as[12].

$$
f_{S}=1-\left(\frac{T_{S}-T}{T_{S}-T_{l}}\right)^{\left(\frac{1}{1-k}\right)}
$$

and;

$$
f_{L}=1-\left(\frac{T_{m}-T}{T_{m}-T_{l}}\right)^{\left(\frac{1}{1-k}\right)}
$$
alloy.

where, $T_{s}, T_{1}$ and $T_{m}$ are equilibrium solidus, liquidus and melting temperatures of the

Simulation of solidification curves and experimental validation

Aluminium A319.2 grade commercial Al-Si-Cu alloy was selected for the present study. The nominal alloy composition used is presented in Table I. 2021b educational version of Thermo-Calc software package was employed to simulate their non-equilibrium solidification characteristics.

TABLE I Chemical Composition of A319.2 Alloy

\begin{tabular}{c|c|c|c|c|c|c}
\hline $\mathrm{Si}$ & $\mathrm{Cu}$ & $\mathrm{Mg}$ & $\mathrm{Zn}$ & $\mathrm{Fe}$ & $\mathrm{Ti}$ & $\mathrm{Al}$ \\
\hline $5-7$ & $3-5$ & 0.5 & 0.5 & 0.5 & 0.02 & Remaining \\
\hline
\end{tabular}

The Scheil solidification module of the package and the in-built Aluminium Demo database 4.0 were used to simulate the solidification curves of the selected alloy. The alloying elements other than copper and silicon are not examined in depth since their amounts in the alloy system are quite low for considering them as major alloying elements. Thus, the elements considered for simulating the solidification curve were restricted to $\mathrm{Al}, \mathrm{Cu}$ and $\mathrm{Si}$. Initially, a pilot trial on simulation was done with $\mathrm{Al}-6 \mathrm{Si}-4 \mathrm{Cu}$ alloy. The data points of the simulated curves were collected and post-processed for deriving alloy's thermodynamic parameters for thixoforming. For the validation of simulation studies, the alloys of required chemistry were melted and poured to a cup-thermocouple assembly and the change in temperature during its solidification is collected as a function of time (computer aided cooling curve of alloys) with the help of thermocouple and computer connected data acquisition system. The cooling curve thus obtained is converted to solidification curve by partial integration technique, the details of cooling curve to solidification curve conversion is reported elsewhere[14], [18].

\section{Results and discussions}

Vertical section of Al-6Si-XCu equilibrium phase diagram

The vertical section of the Al-6Si-xCu diagram is depicted in Fig. 2 and it indicates the major phase transformations. Based on the phase diagram shown in Fig. 2, the selected alloy has five phase fields and out of five three are above solidus. 
It can be observed from Fig. 2. that, for the selected $\mathrm{Al}-6 \mathrm{Si}-4 \mathrm{Cu}$ alloy, the equilibrium phase transformations prior to complete solidification are as follows. Liquid $\rightarrow$ Liquid $+\alpha-$ Aluminium transformation corresponding to nucleation of primary aluminium phase starts at $610{ }^{\circ} \mathrm{C}$ and carry on till $562{ }^{\circ} \mathrm{C}$. From $562{ }^{\circ} \mathrm{C}$ onwards nucleation of eutectic Si initiates with transformation path as: Liquid $+\alpha-$ Aluminium $\rightarrow$ Liquid $+\alpha-$ Aluminium $+S i$. This transformation ends at the solidus point of $526{ }^{\circ} \mathrm{C}$ and further, some solid-state phase formations can be observed from the simulated phase diagram.

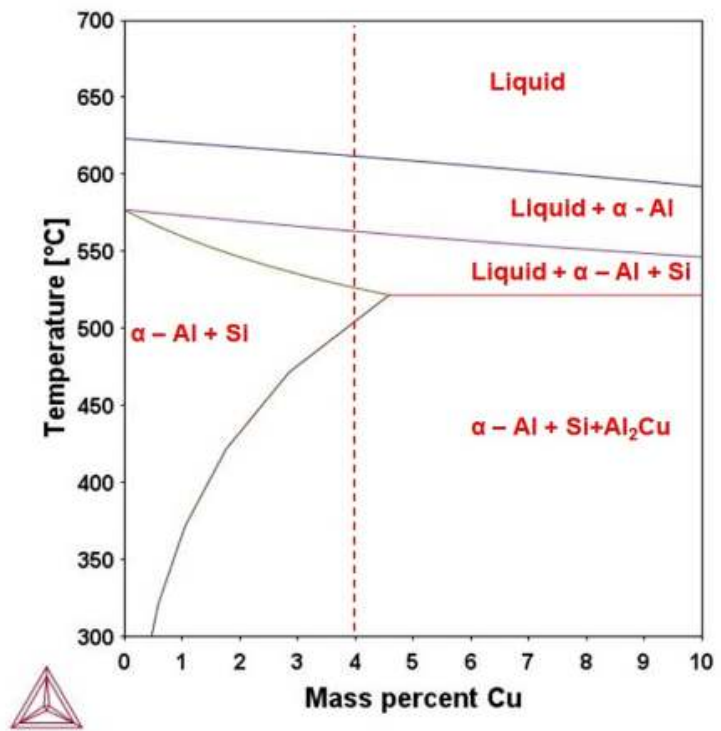

Fig.2. Vertical section of Al-6Si-XCu equilibrium phase diagram.

Other transformations predicted in the phase diagram are Liquid $+\alpha-$ Aluminium $+S i \rightarrow$ $\alpha-$ Aluminium $+\mathrm{Si}$ and $\alpha-$ Aluminium $+\mathrm{Si} \rightarrow \alpha-$ Aluminium $+\mathrm{Si}+\mathrm{Al}_{2} \mathrm{Cu}$ formations. $\mathrm{Al}_{2} \mathrm{Cu}$ formation initiates at a temperature of $507{ }^{\circ} \mathrm{C}$. These are the major equilibrium transformations predicted for the chosen alloy composition by the Thermo-Calc software through CALPHAD approach within the calculation limit of the used database and selected alloying elements.

Scheil solidification diagram

The Scheil solidification diagram for the selected alloy composition is simulated using the in-built Scheil solidification module of Thermo-Calc software. The curve thus obtained is presented in Fig. 3. Fig. 3. shows the major non-equilibrium liquid state phase transformations in the Al-6Si-4Cu alloy. 


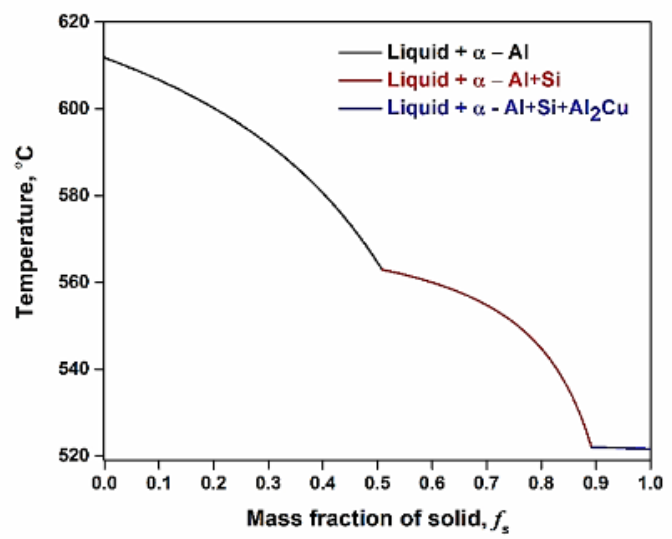

Fig. 3. Scheil solidification diagram of Al-6Si-4Cu alloy.

The predicted Scheil solidification curve (Fig. 3.) points out that, the liquidus point of Al$6 \mathrm{Si}-4 \mathrm{Cu}$ alloy is situating at $611^{\circ} \mathrm{C}$ temperature and its solidus is lying at $521{ }^{\circ} \mathrm{C}$. In line with the equilibrium phase diagram shown in Fig. 2., the liquidus and solidus of alloy are at 610 and $526{ }^{\circ} \mathrm{C}$ respectively. The prediction of solidus and liquidus point temperatures of the alloy by the two models are closely matching and it ensures the accuracy of the approach. The marginal variation in the predicted temperature, especially solidus, can be rationalized by the difference in equilibrium and non-equilibrium models of transformations. The Scheil curve in Fig. 3. indicates that the solidification of liquid alloy starts with nucleation of $\alpha-A l$ at $610{ }^{\circ} \mathrm{C}$. Also, the nucleation of eutectic $\mathrm{Si}$ is found to initiate at $559{ }^{\circ} \mathrm{C}$ at a corresponding solid fraction of 0.5 . Further, the third set of phase transformation starts at $521{ }^{\circ} \mathrm{C}$ and it continues till the complete conversion of the remaining liquid into solid. From Fig. 3., it can also be perceived that the binary eutectic reaction starts at $559^{\circ} \mathrm{C}$ and $f_{S}=0.5$ and the ternary eutectic reaction occurs at $521{ }^{\circ} \mathrm{C}$ and $f_{S}=0.86$. The small variation in the solidification phase transformation path is mainly attributed to the differences in equilibrium and non-equilibrium models.

Thermodynamic Parameters for Semi-solid Processing

The thermodynamic parameters mentioned in section II were calculated from the Scheil solidification curve mentioned in Fig. 3. The calculated parameters are listed in Table II for ready references.

TABLE II Predicted Thermodynamic Parameters for Semi-solid Processing of Al-6Si$4 \mathrm{Cu}$ Alloys 


\begin{tabular}{|c|c|c|c|}
\hline $\begin{array}{l}\text { Sl. } \\
\text { No. }\end{array}$ & Parameter & $\begin{array}{c}\text { Values from } \\
\text { simulated } \\
\text { curve }\end{array}$ & $\begin{array}{c}\text { Nominal } \\
\text { range of } \\
\text { values } \\
{[9],[10]}\end{array}$ \\
\hline 1 & $\begin{array}{l}\text { Range of } \\
\text { Solidification } \\
\text { Temperature } \\
\left(\Delta T_{S-L}\right), \\
{ }^{\circ} \mathrm{C}\end{array}$ & 90 & $30-120$ \\
\hline \multirow[t]{2}{*}{2} & \multirow{2}{*}{$\begin{array}{l}\text { Working } \\
\text { Window } \\
\text { Temperature } \\
\left(\Delta T_{w w}\right)^{\circ} \mathrm{C}\end{array}$} & $\begin{array}{c}9 \text { for } \\
\text { thixoforming }\end{array}$ & \multirow{2}{*}{$10-30$} \\
\hline & & $\begin{array}{c}28 \text { for } \\
\text { rheocasting }\end{array}$ & \\
\hline \multirow[t]{2}{*}{3} & \multirow{2}{*}{$\begin{array}{l}\text { Fraction } \\
\text { solid } \\
\text { sensitivity } \\
\left(d f_{s} / d T\right)^{\circ} \mathrm{C}^{-1}\end{array}$} & $\begin{array}{c}0.022 \text { for } \\
\text { thixoforming }\end{array}$ & \multirow{2}{*}{$\begin{array}{c}\text { Less } \\
\text { than } \\
0.020\end{array}$} \\
\hline & & $\begin{array}{l}0.0073 \text { for } \\
\text { rheocasting }\end{array}$ & \\
\hline 4 & $\begin{array}{l}\text { Position of } \\
\text { highest } \\
\text { knee point }\end{array}$ & 0.5 & $\begin{array}{c}\text { Between } \\
f s=0.4 \\
\text { and } 0.7\end{array}$ \\
\hline
\end{tabular}

From Table II, it can be inferred that the main parameters, except working window temperature and Temperature sensitivity of Solid fraction for thixoforming fall in the nominal value range. Working window is a crucial parameter for semi-solid processing, especially to control the thixoforming process. A too low working window like $9{ }^{\circ} \mathrm{C}$ may increase the possibility of increasing or decreasing the slurry solid fraction in its mushy zone. The lack of temperature control in the working window range can cause two major effects. The reduction in working temperature than the lower limit can increase the solid content of slurry and thus it can increase the pressing load or damage the forming die. Similarly, the increase in working temperature than the allowed limit can increase the liquid content of the slurry and while forming it may lead to flashing of slurry and/or die leakage. Likewise, the temperature sensitivity of solid fraction can also affect the process; however, the value is close to the nominal ranges. The alloy composition is the primary determinant of slurry properties and it has a close relationship with solidification characteristics. Hence, to further optimise the alloy composition for a higher working window temperature for thixoforming of the selected alloy, a set of Scheil solidification curve simulation trials with the variation of $\mathrm{Si}$ and $\mathrm{Cu}$ content in the allowed range of A319.2 commercial grade alloy were performed according to Taguchi L9 orthogonal array. The L9 orthogonal array is formed with the help of Minitab software. The levels of factors are selected in the chemical composition range of A319.2 alloy. The L9 orthogonal arrays for the combinations of Al-Si-Cu alloys were presented in Table III.

TABLE III L9 Orthogonal Array of Al-Si-Cu Alloy Compositions for Simulations 


\begin{tabular}{l|c|c|c}
\hline Combinations & $\begin{array}{c}\text { Si } \\
\text { (wt. \%) }\end{array}$ & $\begin{array}{c}\text { Cu } \\
(\mathbf{w t . ~ \% )}\end{array}$ & $\begin{array}{c}\text { Al } \\
\text { (wt. \%) }\end{array}$ \\
\hline Set 1 & 5 & 3 & 92 \\
\hline Set 2 & 5 & 4 & 91 \\
\hline Set 3 & 5 & 5 & 90 \\
\hline Set 4 & 6 & 3 & 91 \\
\hline Set 5 & 6 & 4 & 90 \\
\hline Set 6 & 6 & 5 & 89 \\
\hline Set 7 & 7 & 3 & 90 \\
\hline Set 8 & 7 & 4 & 89 \\
\hline Set 9 & 7 & 5 & 88 \\
\hline
\end{tabular}

The Scheil solidification simulation results for the combination of alloy systems as per L9 array were shown in Fig. 4 and the predicted parameters were presented in Table IV. A noticeable change in solidification characteristics can be observed in the alloy systems. The change in alloy composition within its allowed range itself alters the liquidus point temperature to vary from 621 to $601{ }^{\circ} \mathrm{C}$. However, the variations in the compositions did not affect the solidus temperature and it remains the same for all the nine sets of combinations.

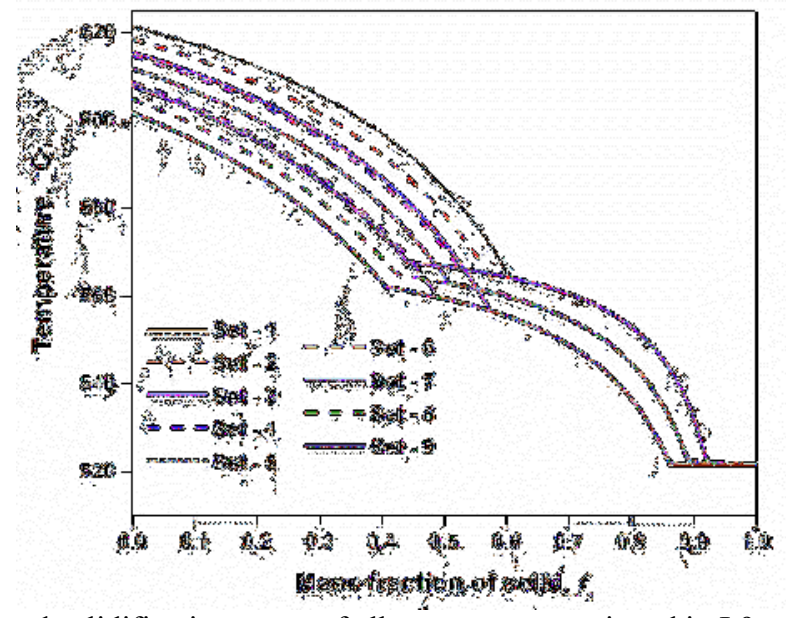

Fig.4. Simulated solidification curve of alloy systems mentioned in L9 orthogonal array

It can be observed from Table IV that, in the perspective of semi-solid processing criteria, all the nine alloys have their binary eutectic knee point located between the preferred range of 0.4 to $0.7 \mathrm{fs}$.

TABLE IV Predicted Thermodynamic Parameters for Different Al-Si-Cu alloy compositions 


\begin{tabular}{l|c|c|c|c|c}
\hline Combinations & $\Delta^{\Delta} \mathbf{T}_{\text {S-L }},{ }^{\circ} \mathbf{C}$ & $\begin{array}{c}\Delta \mathbf{T}_{\mathrm{ww}} \text { for } \\
\text { thixoforming, } \\
{ }^{\circ} \mathbf{C}\end{array}$ & $\begin{array}{c}\Delta \mathbf{T}_{\mathrm{ww}} \text { for } \\
\text { rheocasting, } \\
{ }^{\circ} \mathbf{C}\end{array}$ & $\begin{array}{c}-\left(d f_{s} / d T\right) \text { for } \\
\text { thixoforming } \\
{ }^{\circ} \mathbf{C}^{-1}\end{array}$ & $\begin{array}{c}-\left(d f_{s} / d T\right) \text { for } \\
\text { rheocasting } \\
{ }^{\circ} \mathbf{C}^{-1}\end{array}$ \\
\hline Set 1 & 100 & 24 & 21 & 0.0085 & 0.0094 \\
\hline Set 2 & 97 & 24 & 23 & 0.0085 & 0.0087 \\
\hline Set 3 & 94 & 23 & 25 & 0.0087 & 0.0088 \\
\hline Set 4 & 93 & 10 & 25 & 0.020 & 0.0078 \\
\hline Set 5 & 90 & 9 & 28 & 0.022 & 0.0073 \\
\hline Set 6 & 87 & 11 & 27 & 0.019 & 0.0069 \\
\hline Set 7 & 86 & 6 & 19 & 0.032 & 0.0103 \\
\hline Set 8 & 83 & 8 & 18 & 0.024 & 0.0109 \\
\hline Set 9 & 80 & 11 & 18 & 0.019 & 0.0118 \\
\hline
\end{tabular}

The effect of Alloying elements on the thermodynamic parameters has been analysed and depicted in Fig. 5. Fig. 5 reveals that the alloying elements have significant effects on working temperature and temperature sensitivity of solid fraction in semi-solid processing range. Fig. 5 (a) shows the effect of alloying elements on the working window of alloy and Fig. 5 (b) shows the relation between temperature sensitivity of solid fraction and alloy composition. The common observation from Fig. 5 (a) and (b) is that the alloy with a higher fraction of $\mathrm{Cu}(4$ and $5 \mathrm{wt} . \%$ ) are not preferred for thixoforming. The lower working window and higher sensitivity of solid fraction changes in the range of parameters for thixoforming can be ascribed to the same. However, all the nine alloy combinations are well suited for the rheocasting process. Fig. 5 (b) indicate that, between the solid fraction of 0.3 to 0.5 , the nine set of alloys have a smaller amount of solid fraction change sensitivity $\leq \sim 1 \%$. It ensures that, the unit change in temperature causes nearly $1 \%$ increment in the solid content of the slurry. Contrarily, for the alloys with 4 and $5 \%$ of $\mathrm{Cu}$ and $5-7 \%$ of Si, the solid fraction change sensitivity for unit change in temperature is $\geq 2 \%$. A lower working window of nearly 8-10 ${ }^{\circ} \mathrm{C}$ and a higher rate of solid transformation for such alloy compositions (set 4 to 9) puts the control of thixoforming in a bottleneck. In addition, it can be noticed from the Fig. 5 that, for a fixed fraction of $\mathrm{Cu}$, the amount of $\mathrm{Si}$ in alloys has a marginal effect on the parameters such as working window range and temperature sensitivity. 

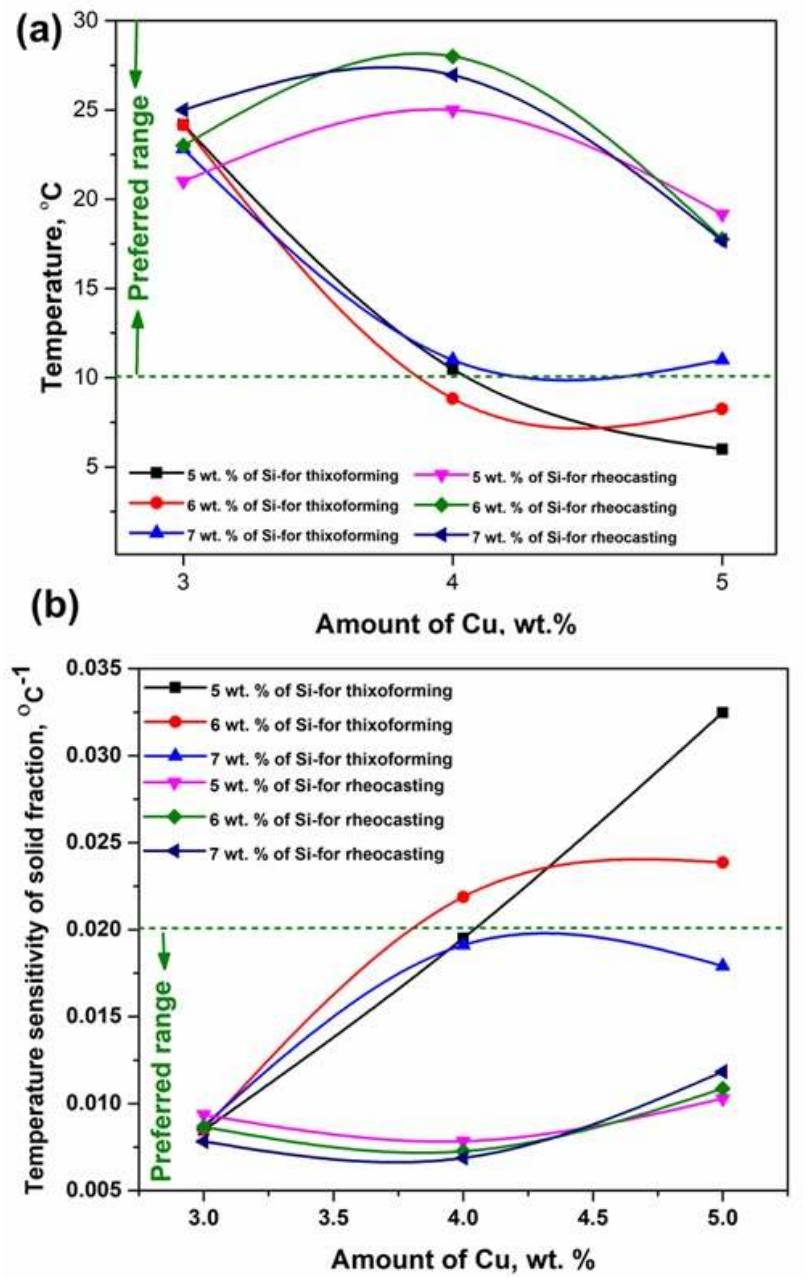

Fig.5. Effect of alloying element on the a) working window and b) temperature sensitivity of solid fraction of Al-xSi-yCu alloys $(x=3,4,5$ and $y=5,6,7)$

Further, Table IV abridges the thermodynamic parameters of alloy combinations and the it shows that as the Si content increases, the overall solidification range is reduced and within a fixed amount of $\mathrm{Si}$, the increment in $\mathrm{Cu}$ further reduces the solidification ranges of the alloy combinations. It can be concluded that $\mathrm{Al}-5 \mathrm{Si}-\mathrm{xCu}(\mathrm{x}=3,4$ and 5) alloys have a higher range of solidification interval compared to other alloys and their temperature sensitivity of solid fraction for both thixoforming and rheocasting are falling in the required ranges. Among the $\mathrm{Al}-5 \mathrm{Si}-\mathrm{xCu}$ alloy systems, the combination of $\mathrm{Al}-5 \mathrm{Si}-4 \mathrm{Cu}$ has the best suitable parameters for semi-solid processing. The apparent changes in volumetric coefficient of thermal expansion (CTE) are simulated for $\mathrm{Al}-5 \mathrm{Si}-4 \mathrm{Cu}$ and $\mathrm{Al}-7 \mathrm{Si}-3 \mathrm{Cu}$ alloy (one with best and least suitable parameters) and are shown in Fig. 6. 

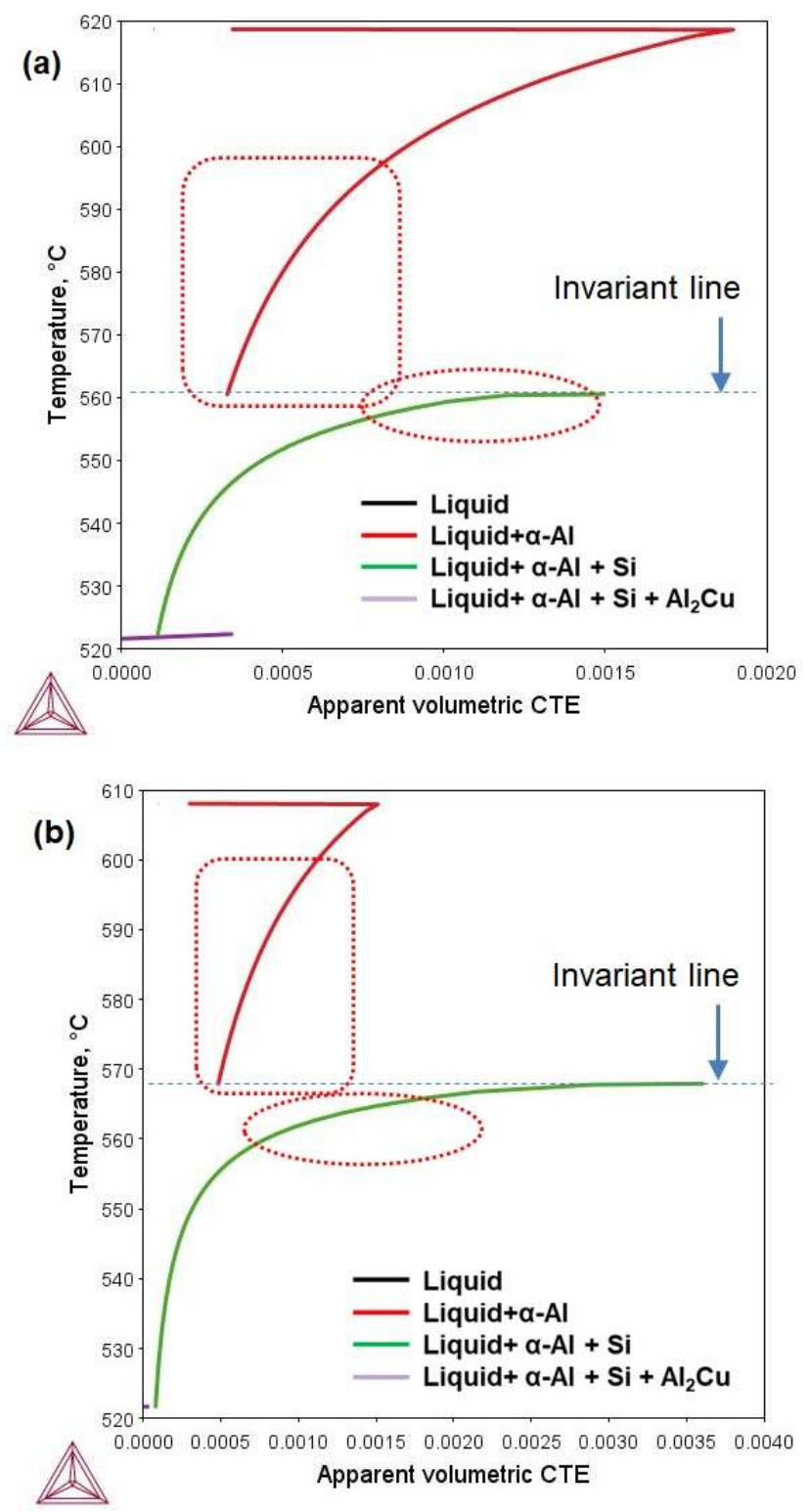

Fig. 6. Apparent volumetric coefficient of thermal expansion for (a) $\mathrm{Al}-5 \mathrm{Si}-4 \mathrm{Cu}$ alloy and (b) Al-7Si-3Cu alloy

The apparent change in volumetric CTE in the semi-solid processing region is marked in Fig. 6. In Fig. 6, there are two regimes; the red coloured curve shows the variation in the volumetric contraction of Liquid $\rightarrow$ Liquid $+\alpha$ Al Phase and the green one represents the 
second transformation (Liquid $+\alpha \mathrm{Al} \rightarrow$ Liquid $+\alpha \mathrm{Al}+\mathrm{Si}$ ). The invariant line corresponding to the binary eutectic transformation is also marked in Fig. 6. It can be inferred from Fig. 6 (a) that a higher CTE change occurs after the eutectic transformation than conditions prior to eutectic transformations. However, the rate of change of CTE is higher till the eutectic point and afterwards, a slow rate of CTE change can be observed. Contrariwise, in the case of Al7Si-3Cu alloy (Fig. 6. (b)), the amount of variation in CTE after the binary eutectic transformation is higher than that before the transformation. In addition, interestingly, the rate of change of CTE till the eutectic point is higher than that after the eutectic point. This can corroborate the difference in solidification behaviour of two alloy systems and also attribute to the thermodynamic parameter difference in two alloys.
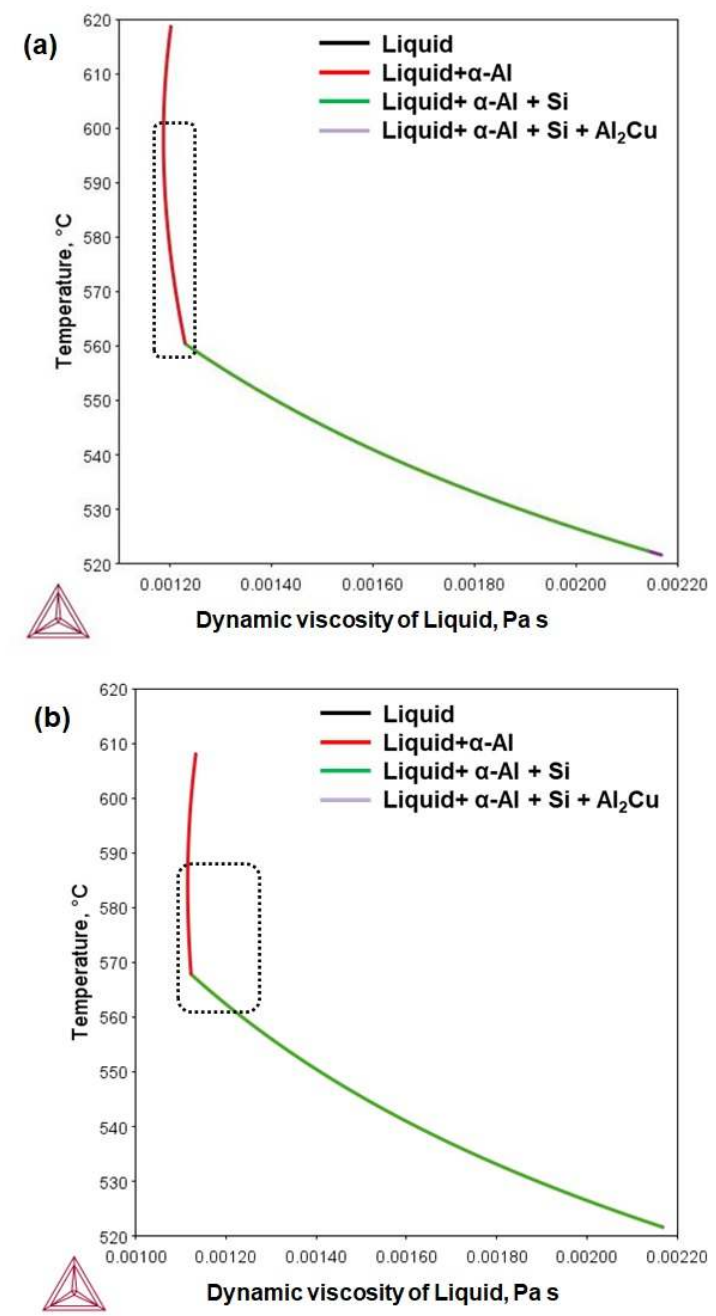

Fig. 7. Dynamic viscosity of liquid phase in a) Al-5Si-4Cu alloy and b) Al-7Si-3Cu alloy 
Fig. 7. depicts the dynamic viscosity of the liquid phase in $\mathrm{Al}-5 \mathrm{Si}-4 \mathrm{Cu}$ and $\mathrm{Al}-7 \mathrm{Si}-3 \mathrm{Cu}$ alloy. Fig. 7. (a) indicates that, in the marked region of semi-solid state, the alloys have a lower value of dynamic viscosity $(\sim 0.0011 \mathrm{~Pa} \mathrm{~s})$ and it remains constant throughout the semisolid region. However, the dynamic viscosity of $\mathrm{Al}-7 \mathrm{Si}-3 \mathrm{Cu}$ alloy (Fig. 7. (b)) varies from 0.0011 to $0.0014 \mathrm{~Pa}$ s. Shear deformation is the key factor of thixotropy and thixotropy is the basic science behind semi-solid processing. Further, the shear force required to shear deformation is directly proportional to dynamic viscosity. From the Fig. 6 and 7 it can be deduced that; the alloy composition affects the volumetric expansion and contraction of the semi-solid slurry and also the shear force required to induce thixotropy effect to transform the slurry as a Newtonian fluid during the period of semi-solid processing.

Validation of Simulation Data with Experimental Curves

The simulation results obtained in the present study were compared with experimental results to validate the simulation process and results. For the same, the cooling curve of Al$5 \mathrm{Si}-4 \mathrm{Cu}$ alloy obtained from computer aided cooling curve analysis is utilized.

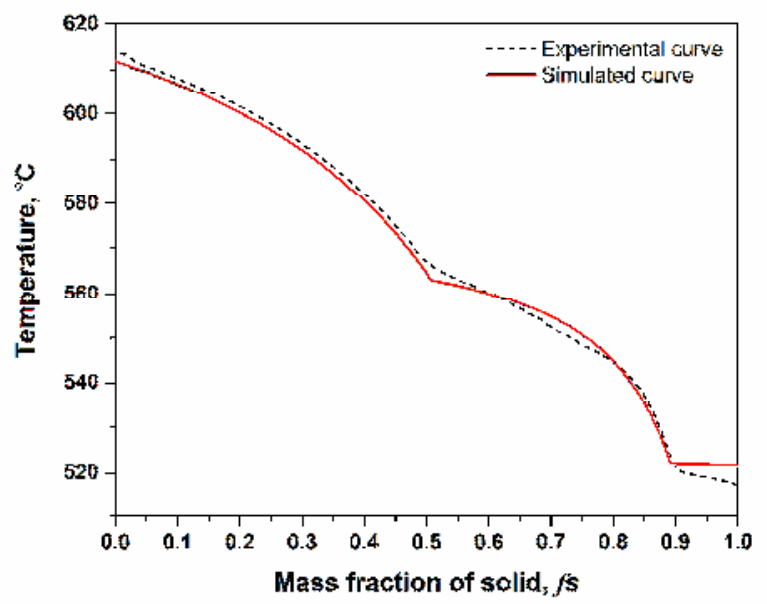

Fig.8. Experimental vs. Simulated Solidification Curve of Al-5Si-4Cu alloy

The experimental solidification curve and simulation curve are compared in Fig. 8. and the thermodynamic parameters deduced are compared in Table V.

TABLE V Predicted Thermodynamic Parameters Vs. Experimental data

\begin{tabular}{l|c|c|c|c|c}
\hline Combinations & $\begin{array}{c}\Delta \mathrm{T}_{\mathrm{S}-\mathrm{L}}, \\
{ }^{\circ} \mathrm{C}\end{array}$ & $\begin{array}{c}\Delta \mathrm{T}_{\mathrm{ww}} \text { for } \\
\text { thixoforming, } \\
{ }^{\circ} \mathrm{C}\end{array}$ & $\begin{array}{c}\Delta \mathrm{T}_{\mathrm{ww}} \text { for } \\
\text { rheocasting, } \\
{ }^{\circ} \mathrm{C}\end{array}$ & $\begin{array}{c}-\left(d f_{s} / d T\right) \text { for } \\
\text { thixoforming, } \\
{ }^{\circ} \mathrm{C}^{-1}\end{array}$ & $\begin{array}{c}-\left(d f_{s} / d T\right) \text { for } \\
\text { rheocasting, } \\
{ }^{\circ} \mathrm{C}^{-1}\end{array}$ \\
\hline Simulation & 94 & 23 & 25 & 0.0087 & 0.0088 \\
\hline Experimental & 99 & 26 & 16 & 0.0076 & 0.0112 \\
\hline
\end{tabular}

The experimental curve and simulated curve presented in Fig. 8 are closely matching and the thermodynamic parameters deduced from the simulated curve are closely matching with the data from the experimental curve (Table V). Hence it corroborates that CALPHAD approach is effective to simulate and identifying the thixoforming parameters. information and standard abbreviations. 


\section{Conclusions}

The current study leads to the following conclusions:

Thermodynamic simulation and cooling curve analysis can be used to evaluate semi-solid processing parameters. Among them, simulation analysis is more effective and time conserving.

The CALPHAD analysis shows that, even if the alloy composition varies within the ASTM standard range, it can affect the semi-solid processing parameters and also the physical properties such as dynamic viscosity and apparent coefficient of thermal expansion.

From the evaluation of $\mathrm{Al}-\mathrm{xSi}-\mathrm{yCu}$ alloy $(\mathrm{x}=5,6,7$ and $\mathrm{y}=3,4,5)$ systems, it can be inferred that a composition of $\mathrm{Al}-5 \mathrm{wt} . \% \mathrm{Si}-4 \mathrm{wt} . \% \mathrm{Cu}$ alloy is amenable for semi-solid processing such as thixoforming and rheocasting.

\section{Acknowledgment}

The authors are grateful to The Management, PSG College of Technology, Coimbatore, India 641004 for providing the essential support to complete this study.

\section{References}

[1] S. Nafisi and R. Ghomashchi, "Semi-Solid Processing of Alloys and Composites," Metals (Basel), vol. 9, no. 5, pp. 526-526, 2019.

[2] M. C. Flemings, "Behavior of metal alloys in the semisolid state," Metall. Trans. A, vol. 22, no. 5, pp. 957-981, 1991.

[3] H. V. Atkinson, "Semisolid processing of metallic materials," Mater. Sci. Technol, vol. 26, no. 12, pp. 1401-1413, 2010.

[4] R. Chen, S. Liang, D. Wu, and E. Han, "Consideration of Castability and Formability for New Magnesium Alloys," Open J. Met, vol. 02, no. 01, pp. 8-17, 2012.

[5] M. Kiuchi and R. Kopp, "Mushy/Semi-Solid Metal Forming Technology

[6] - Present and Future," CIRP Ann, vol. 51, no. 2, pp. 61 705-61 708, 2002.

[7] Y. Birol, "Semi-solid processing of the primary aluminium die casting alloy A365," J. Alloys Compd, vol. 473, no. 1-2, pp. 133-138, 2009.

[8] N. H. Husain, A. H. Ahmad, and M. M. Rashidi, "An overview of thixoforming process," IOP Conf. Ser. Mater. Sci. Eng, vol. 257, no. 1, pp. 12 053-12 053, 2017.

[9] E. J. Zoqui, D. M. Benati, C. T. W. Proni, and L. V. Torres, "Thermo- dynamic evaluation of the thixoformability of Al-Si alloys," Calphad Comput. Coupling Phase Diagrams Thermochem, vol. 52, pp. 98-109, 2016.

[10] D. Liu, H. V. Atkinson, and H. Jones, "Thermodynamic prediction of thixoformability in alloys based on the Al-Si-Cu and Al-Si-Cu-Mg systems," Acta Mater, vol. 53, no. 14, pp. 3807-3819, 2005.

[11] Y. D. Li, D. Apelian, B. Xing, Y. Ma, and Y. Hao, "Commercial AM60 alloy for semisolid processing: Alloy optimization and thermodynamic analysis," Trans. Nonferrous Met. Soc. China (English Ed, vol. 20, no. 9, pp. 60 341-60 342, 2010.

[12] A. Camacho, H. V. Atkinson, P. Kapranos, and B. B. Argent, "Thermo- dynamic predictions of wrought alloy compositions amenable to semi- solid processing," Acta Mater, vol. 51, no. 8, pp. 2319-2330, 2003.

[13] M. S. Salleh, M. Z. Omar, J. Syarif, M. N. Mohammed, and K. S. Al- hawari, "Thermodynamic simulation on thixoformability of aluminium alloys for semi-solid metal processing," Int. J. Math. Comput. Simul, vol. 7, no. 3, pp. 286-293, 2013.

[14] E. Tzimas, A. Zav, . E. Tzimas, and A. Zavaliangos, "Evaluation of volume fraction of solid in alloys formed by semisolid processing," J. Mater. Sci, vol. 35, no. 21, pp. 5319-5329, 2000. 
[15] C. Muthuraja, A. Akalya, R. R. Ahmed, J. Nampoothiri, I. Balasundar, and K. R. Ravi, "Experimental investigation and thermodynamic calcu- lation of the phase equilibria in the Mg-rich region of Mg-Sn-Y alloys," J. Alloys Compd, vol. 695, pp. 3559-3572, 2017.

[16] A. Kroupa, "Modelling of phase diagrams and thermodynamic properties using Calphad method Development of thermodynamic databases," Comput. Mater. Sci, vol. 66, pp. 3-13, 2013.

[17] J. Nampoothiri, B. Raj, and K. R. Ravi, "Role of Ultrasonic Treatment on Microstructural Evolution in A356/TiB2 In-Situ Composite," Trans. Indian Inst. Met, vol. 68, no. 6, pp. 11011106, 2015.

[18] J. Nampoothiri, C. Muthuraja, I. Balasundar, and K. R. R. Ravi, "Mi- crostructure Evolution during Semi-solid Isothermal Holding of Liquidus Cast Strontium-Modified A356 Alloy," Trans. Indian Inst. Met, vol. 71, no. 11, pp. 2707-2712, 2018.

[19] J. Nampoothiri, I. Balasundar, B. Raj, B. S. Murty, and K. R. Ravi, "Porosity alleviation and mechanical property improvement of strontium modified A356 alloy by ultrasonic treatment," Mater. Sci. Eng. A, vol. 724, pp. 586-593, 2018. 